\title{
From numerical prototypes to real models: a progressive study of aerodynamic parameters of nonconventional concrete structures with Computational Fluid Dynamics
}

\section{De protótipos numéricos a modelos reais: Um estudo progressivo de parâmetros aerodinâmicos de estruturas não convencionais de concreto utilizando a Dinâmica dos Fluidos Computacional}

C. V. S. SARMENTO carlos.vitor@ufpe.br https://orcid.org/0000-0002-2808-5996

A. O. C. FONTE a antoniooscardafonte@gmail.com https://orcid.org/0000-0003-2943-2184

L. J. PEDROSO lineu@unb.br https://orcid.org/0000-0002-2734-3260

P. M. V. RIBEIRO paulo.vribeiro@ufpe.br https://orcid.org/0000-0002-9261-8953

\begin{abstract}
The practical evaluation of aerodynamic coefficients in unconventional concrete structures requires specific studies, which are small-scale models evaluated in wind tunnels. Sophisticated facilities and special sensors are needed, and the tendency is for modern and slender constructions to arise with specific demands on their interaction with the wind. On the other hand, the advances obtained in modern multi-core processors emerge as an alternative for the construction of sophisticated computational models, where the Navier-Stokes differential equations are solved for fluid flow using numerical methods. Computations of this kind require specialized theoretical knowledge, efficient computer programs, and high-performance computers for large-scale calculations. This paper presents recent results involving two real-world applications in concrete structures, where the aerodynamic parameters were estimated with the aid of computational fluid dynamics. Conventional quad-core computers were applied in simulations with the Finite Volume Method and a progressive methodology is presented, highlighting the main aspects of the simulation and allowing its generalization to other types of problems. The results confirm that the proposed methodology is promising in terms of computational cost, drag coefficient estimation and versatility of simulation parameters. These results also indicate that mid-performance computers can be applied for preliminary studies of aerodynamic parameters in design offices.
\end{abstract}

Keywords: aerodynamics, computational fluid dynamic, special structures, wind.

\section{Resumo}

A avaliação prática dos coeficientes aerodinâmicos em estruturas de concreto não convencionais demanda estudos específicos, que consistem em modelos em escala reduzida, em túnel de vento, para estimativa desses parâmetros. Instalações sofisticadas e sensores especiais são necessários, e a tendência é que as construções modernas, cada vez mais esbeltas e arrojadas, surjam com demandas específicas em relação a sua interação com o vento. Por outro lado, o avanço obtido em processadores modernos do tipo multi-núcleo, emerge como uma alternativa para a construção de modelos computacionais sofisticados, onde as equações diferenciais de Navier-Stokes são resolvidas para o escoamento do fluido por meio de métodos numéricos. Análises deste tipo demandam conhecimento teórico especializado, programas computacionais eficientes e computadores de alta performance para cálculos em larga escala. Este artigo apresenta resultados recentes envolvendo duas aplicações reais em estruturas de concreto, onde os parâmetros aerodinâmicos foram estimados com o auxílio da dinâmica dos fluidos computacional. Computadores convencionais do tipo quad-core foram empregados em simulações com o Método dos Volumes Finitos e uma metodologia progressiva é apresentada, destacando os principais aspectos da simulação e permitindo a sua generalização a outros tipos de problemas. Os resultados confirmam que a metodologia proposta é promissora em termos de custo computacional, estimativa do coeficiente de arrasto e versatilidade dos parâmetros da simulação. Esses resultados confirmam que computadores de média performance podem ser aplicados a estudos preliminares de parâmetros aerodinâmicos em escritórios de projeto.

Palavras-chave: aerodinâmica, dinâmica dos fluidos computacional, estruturas especiais, vento. 


\section{Introduction}

Nowadays the design of slender concrete structures emerges as a current trend. These structures, with irregular geometry, more flexible and susceptible to wind spectra are demanding detailed analysis of aerodynamic effects. These forces affect several structural elements, including modern facades. In this way, the evaluation of wind forces acting on modern concrete structures requires detailed analysis procedures, some not even covered by design prescriptions (Tapajos et al [2], Oda [3], Adnan and Suradi [4], Bhandari et al [5] and Biasioli et al [6]).

Aerodynamics is a field of study widely explored by aerospace and automotive industries in search of optimized solutions and user safety. Similarly, aerodynamics applied to buildings aims to attenuate dynamic effects in structures, ensuring safety and comfort to users, as well as maintaining structural integrity. To measure wind actions in structures, several countries have developed technical standards with examples described in Table 1.

These standards provide values for pressure and drag coefficients for standard geometries with the use of tables and abacuses. In the scenario of concrete reinforced structures of irregular geom- etries, such as special buildings, bridges, towers, and other special structures, wind tunnel tests (as depicted in Figure 1) must be carried out. In these tests, reduced models (including the structure itself, nearby buildings and topography) are built in specific and sophisticated facilities, which are properly instrumented through electronic sensors.

Another way to acquire aerodynamic parameters is through Computational Fluid Dynamics (CFD). The aerospace and automotive industries were the pioneers in Computational Wind Engineering (CWE) (Blocken [9]), due to the possibility of performing several numerical simulations of the flow for the same prototype, requiring only the calibration with a few wind tunnel tests. Thus, from a valid computational model it is possible to replace experimental tests, having as main advantages: (i) the low cost of a numerical wind tunnel using computers; (ii) speed of simulations for valuable data acquisition. Recent advances in computer software and hardware have inspired researchers in numerical solutions acting as feasible alternatives to wind tunnel tests. Despite this progress, wind tunnel remains as a reliable choice for structural projects. This is partly due to uncertainties in developing a reliable numerical model. On the other hand, numerous studies have dealt with CWE applied to

\section{Table 1}

Wind design provisions in some countries

\begin{tabular}{cccc}
\hline Country & Standards & Year & Title \\
\hline Germany & DIN 1055-4 & 2005 & Einwirkungen auf tragwerke - Teil 4: Windlasten \\
Brazil & NBR 6123 & 1988 & Forças devido ao vento em edificações \\
Canada & NBCC & 2010 & National building code of Canada \\
USA & ASCE/SEI 7-05 & 2006 & Minimum design loads for buildings and other structures \\
Italy & NTC & 2008 & Technical rules for construction \\
European Countries & EM 1991 - 1-4 & 2005 & Actions on structures- Part 1 - 4: general actions - wind actions \\
Russia & SNIP 2.0107 & 1985 & Loading and excitations \\
Taiwan & ABRI & 2006 & Specifications for building wind-resistant design \\
\hline
\end{tabular}

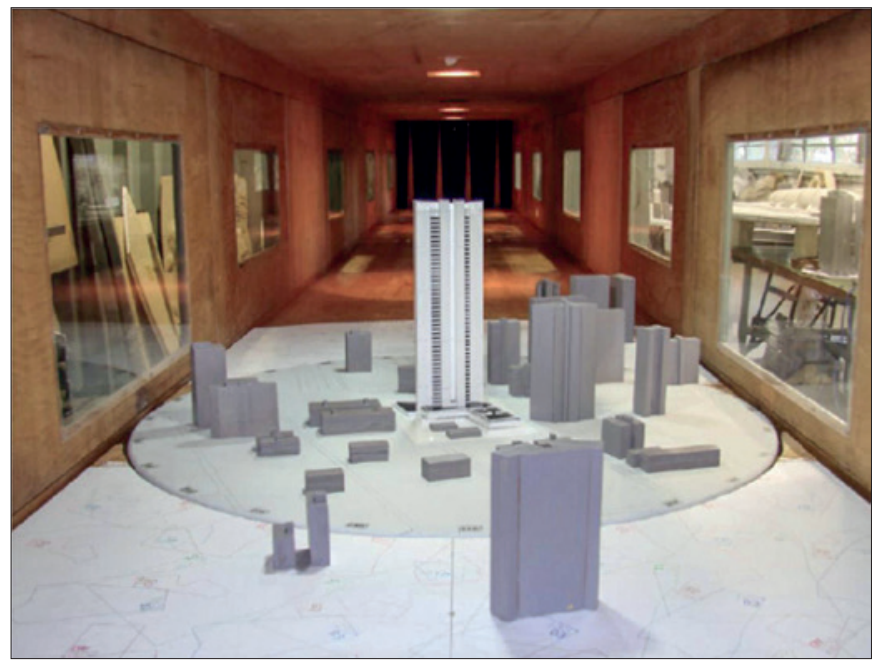

(a)

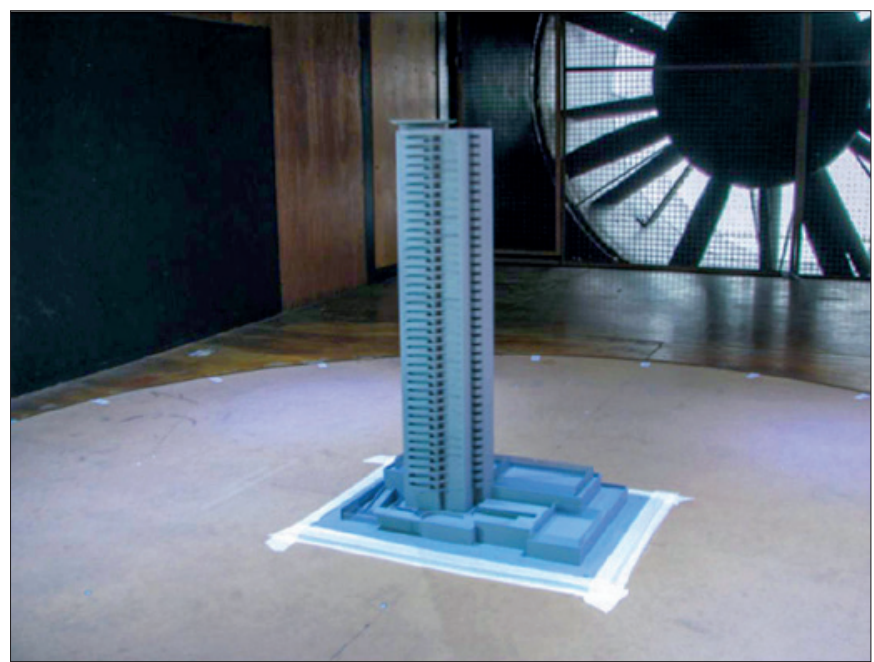

(b)

Figure 1

Wind tunnel lab (a) LAC [7] and (b) IPT [8] 
wind flow around buildings, with a further comparison to experimental data and search for optimal simulation parameters.

Akins et al. [10] presented experimental results of mean force and moment coefficients for a series of thirteen flat-roofed rectangular buildings made with plexiglass. Braun and Awruch [11], using CWE, analyzed viscous incompressible flows over one of these models, and presented a good agreement between numerical and experimental data.

CAARC (Commonwealth Advisory Aeronautical Research Council) building is also an excellent example of extensive numerical simulation and was analyzed in the works of Braun [12], Dagnew and Bitsuamlak [13] and Dagnew and Bitsuamlak [14], among others. In the above-cited cases, the computational domain mimics the wind tunnel aerodynamic test. Therefore, prescriptions must be made to the numerical model regarding length, width, and depth, as well as the position of the target building (or structure). The choice of adequate turbulence model and convergence criteria is also important. These numerical simulations, mostly performed to structures with regular geometry and in the presence of experimental, data serve as a benchmark for advances in CWE. However, a problem arises whenever experimental data is unavailable at the project stage.

Facing the increased application of CFD, some procedures, guides and good practices were presented for computational simulations, as seen in Oberkampf and Trucano [15], Chen and Srebric [16], Moonen et al. [17], Franke et al [18], Reiter [19], Schatzmann and Britter [20], Kim [21] and Rong et al. [22].

With the focus on the advantages of CWE and its application to structural engineering practice, this article proposes a step-by-step procedure for aerodynamic analysis of structures using simple numerical prototypes (with known theoretical or experimental values) for calibration of the final numerical model.

The analysis procedures are based on the use of finite element or finite volume software and address the steps of (i) computational domain construction and structural representation; (ii) mesh generation (domain refinement and mesh quality criteria); (iii) configuration of the problem physics; (iv) convergence study; (v) results analysis.
These procedures allow structural engineers to perform simulations using conventional computers available in design offices and to obtain an initial estimate of aerodynamic parameters(with error minimization and low computational cost). Finally, real-world examples including an aqueduct and a high-rise building are presented and analyzed with the proposed prescriptions.

\section{Governing equations and numerical solution}

\subsection{Governing equations in differential form}

Initially a fixed volume in space is observed with $\vec{v}, \mu$ and $\rho$. Figure 2a presents a control volume, with contour $\mathrm{S}$.

If conservation is guaranteed in $d v$, then it can also be extended to the whole domain $v$. To guarantee mass conservation the differential form presented in equation (1) is defined as the continuity equation:

$\frac{\partial \rho}{\partial t}=\vec{\nabla} \cdot(\rho \vec{V})=0$

Momentum conservation is based on the principle that the sum of forces acting in $d v$ will be equal to the momentum rate of change. Basically, two forces act on an infinitesimal volume: (i) body forces and (ii)surface forces. The governing equation is defined as Navier-Stokes equation for an incompressible fluid and it is described in Cartesian components by:

$\rho\left[\frac{\partial u}{\partial t}+u \frac{\partial u}{\partial x}+v \frac{\partial u}{\partial y}+w \frac{\partial u}{\partial z}\right]=-\frac{\partial \rho}{\partial x}+\rho g_{x}+f_{v x}$

$\rho\left[\frac{\partial v}{\partial t}+u \frac{\partial v}{\partial x}+v \frac{\partial v}{\partial y}+w \frac{\partial v}{\partial z}\right]=-\frac{\partial \rho}{\partial y}+\rho g_{y}+f_{v y}$

$\rho\left[\frac{\partial w}{\partial t}+u \frac{\partial w}{\partial x}+v \frac{\partial w}{\partial y}+w \frac{\partial w}{\partial z}\right]=-\frac{\partial \rho}{\partial z}+\rho g_{z}+f_{v z}$

The set of equation (2)-(4) combined with equation (1) form a system of nonlinear partial differential equations composed of 04 unknowns

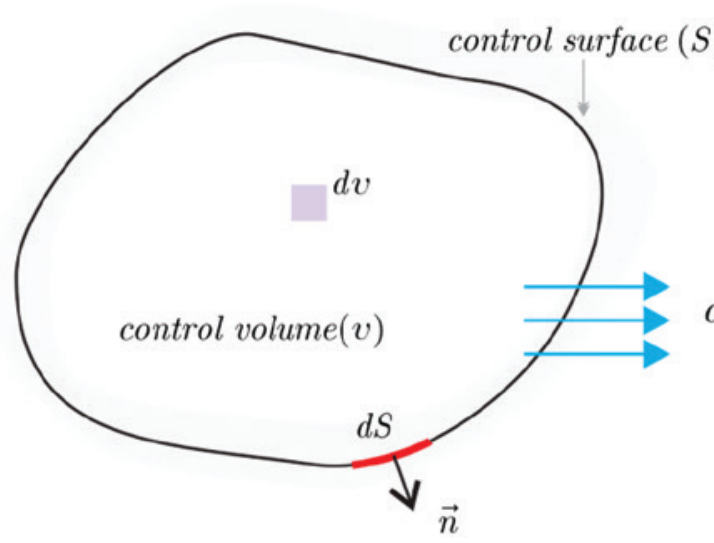

(a)

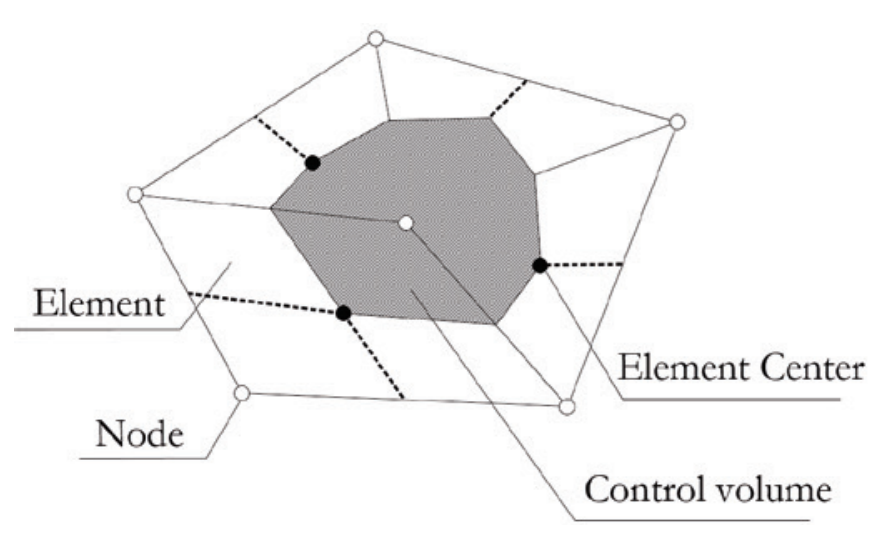

(b)

\section{Figure 2}

Control volume 2D: (a) Fluid flowing through the generic control volume; (b) Typical mesh for a generic control volume 
$(u, v, w$ and $p)$. The inherent difficulties to this problem often require the use of numerical methods for practical solutions.

\subsection{Numerical strategies for computational solution}

A suitable discretization method must be chosen to approximate equation (1)-(4) to a system of discrete algebraic equations in space and time. The most applied and indicated methods to solve
Navier Stokes equation with the Eulerian descriptions in computational simulations of flow around structures is the Finite Volume Method (FVM), as described by Patankar [23], Prakash and Patankar [24], Versteeg and Malalasekera [25] and Ferziger and Peric [26].This method is one of the cornerstones of computational mechanics, due to its versatility and ability to solve differential equations. The FVM comprises a domain discretized through control volumes, as seen in Figure $2 \mathrm{~b}$.In these volumes the mass, the

\section{numerical prototypes}

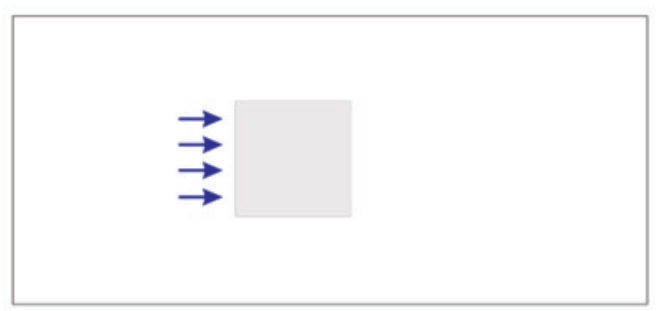

model 1
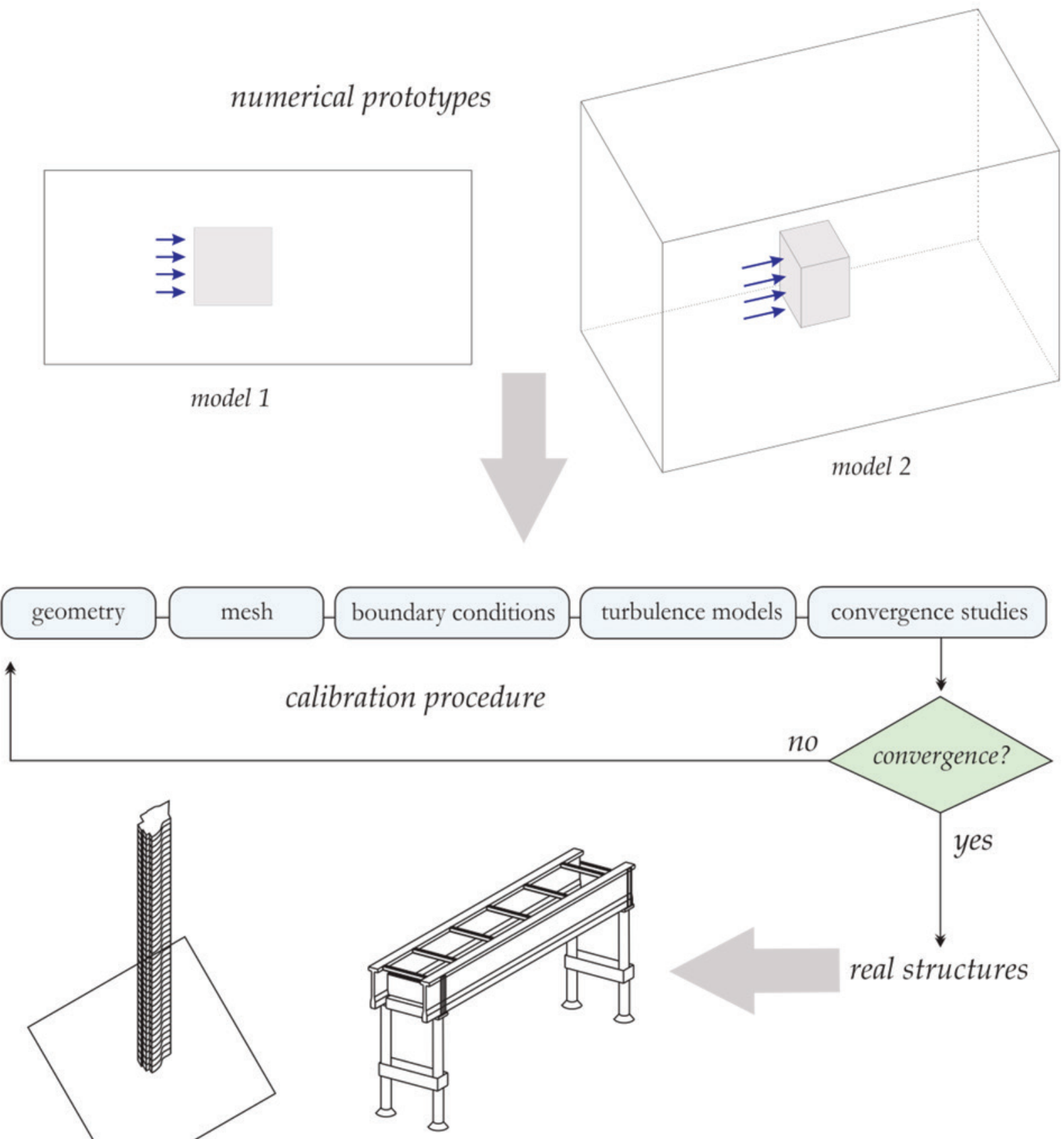

\section{Figure 3}

Proposed methodology 
momentum, and the energy quantities (Equations 1-4) are conserved and based on the nodal variables of the mesh (pressure and velocity). Interpolations are performed for field evaluation at a subdomain (finite volume). This method is conservative and the solution is based on surface integrals, and finite volumes share their surfaces with adjacent ones. The FVM represents convective and diffusive fluxes and in this way this method is one of the most employed methods in CFD.

The above cited numerical methods require turbulence treatment because the contribution of fluctuations to velocity plots in the NavierStokes equations may be practically unpredictable in turbulent flows, and this is due to the large-scale of space and time to be solved (Kun$\mathrm{du}$ and Cohen [27]). Aerodynamic flows in structures are commonly quite turbulent, with a high $\left(>10^{5}\right)$ Reynolds number, defined by:

$R e=\frac{\rho V D}{\mu}=\frac{V D}{v}$

There are basically three ways to solve turbulence in CFD simulations:

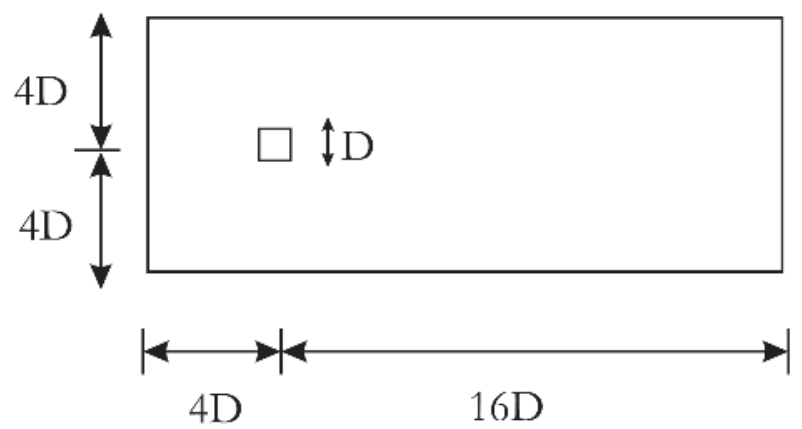

(a) Domain 2D

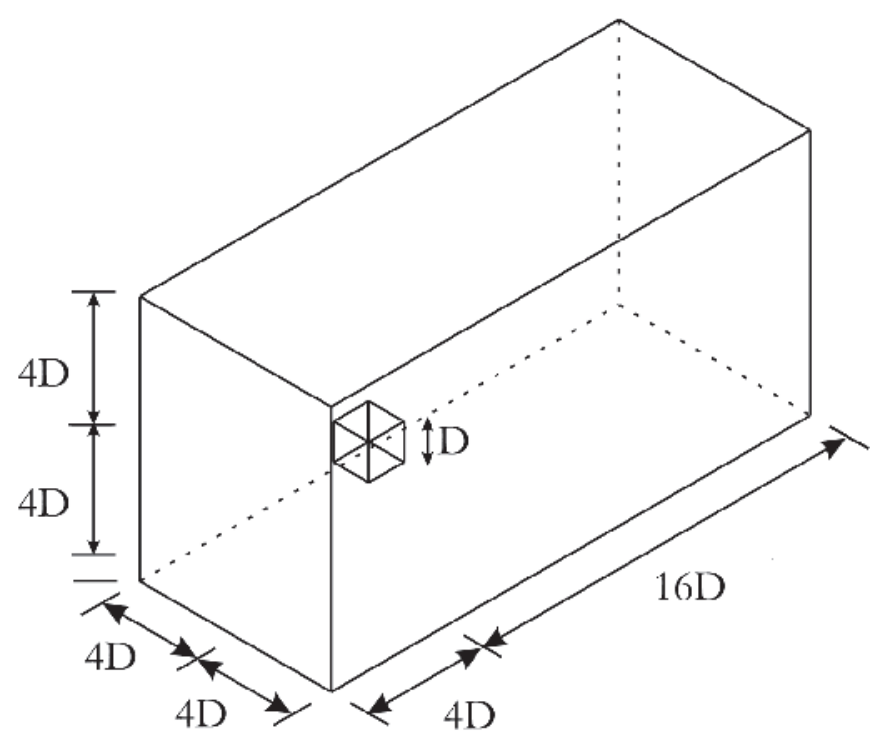

(c) Domain 3D
(I) DNS - Direct Numerical Simulation, which solves numerically, in the smallest time scales, the Navier Stokes equations. In this way, the average Reynolds obtained computationally determines the average flow. For the DNS, the meshes must be extremely refined, restricting applications to supercomputers.

(II) LES - Large Eddy Simulation is based on large-scale solution of turbulent energy. So, the idea is to solve only the large eddies accurately and the effects are approximate of the small scales. The LES model requires less refinement than a DNS model.

(III) RANS - Reynolds Averaged Navier Stokes, based on the Reynold average equations. This model was proposed by Reynolds in 1895 where the approach is based on the decomposition of the variable into mean and fluctuating parts in time. The RANS model solves the turbulent fluctuation for all the scales on each node. When the target is reducing computational cost, the RANS model is usually the first choice.

RANS is the most common choice for fluid dynamic analysis and

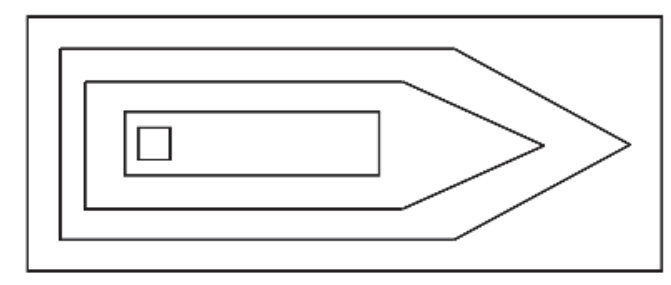

(b) Subdomain 2D

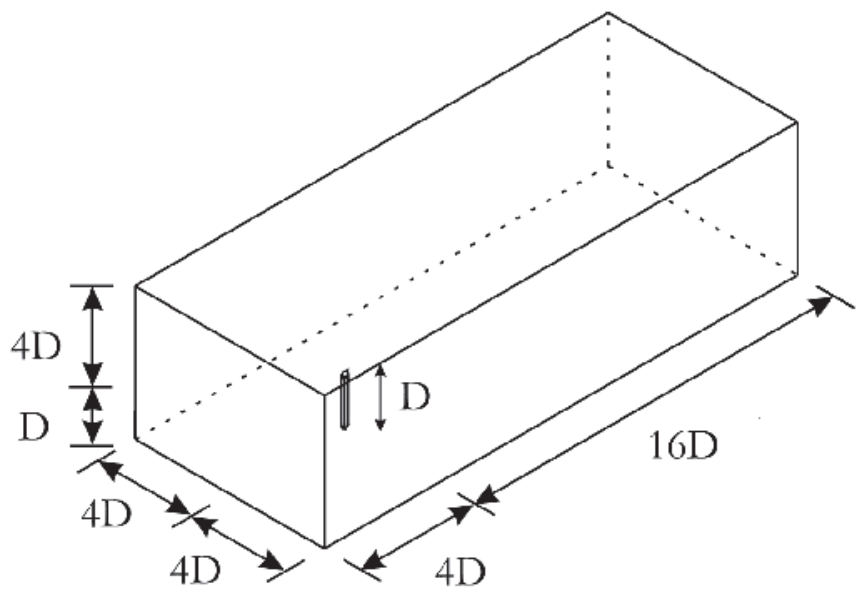

(d) Structures in floor

Figure 4

General dimensional domain 
will be used on this paper. It can be further divided into a series of models, such as Zero Equation Model, Eddy Viscosity Transport Equation, Standard k - $-\varepsilon$ Model, RNG, k- $\omega$, SST, SSG, BSL.

Procedures required estimating the aerodynamic coefficients using numerical methods are described in the next section.

\section{Methodology: from numerical prototypes to the final model}

This procedure starts with a progressive evolution of simple computational models (here defined as numerical prototypes), where numerical calibration is initially performed with reference or experimental results. This step precedes the final computational model, which represents the real structure, and provides the required reliability for numerical simulations. Thus, the reasoning is not only to solve the numerical problem but to construct a numerical model that approximates real conditions and can be used as a numerical wind tunnel.

An overview of the major steps evolved in the current proposal are depicted in Figure 3. These will be detailed in the following sections.

\subsection{Geometry domain}

This procedure mimics the wind tunnel test. The structure is positioned at a given distance from the inlet, thus allowing the generation of turbulence. As for the dimensions, the prescriptions available in Franke et al. [18] are recommended, where the proposed dimensions are shown in Figure 4. It is treated as a Boolean operation, where a computational domain is generated, and the structure is subtracted.

In general, the domain length is selected between 15D and 20D, where $D$ is the characteristic dimension of the section. In this case, there is a greater refinement of volumes in the user-defined region (closer to the object), since the flow is more sensitive to boundary conditions. Because of this, subdomains must be created around the objects and at regions of the floor, to allow different mesh scales for rugosity prescription. Another strategy (commonly seen in the literature for laminar flows) is the use of symmetry. However, it should be noted that the wind flow has turbulent characteristics, so for a given time $t$, what occurs in one half of the domain will not necessarily occur in other.

For two-dimensional flows using 3D codes, a thickness must be imposed to the domain. In practice, a small value is prescribed, avoiding excessive computational cost. The authors propose a value of $D / 20$. For three-dimensional simulations, it is important to maintain a $4 \mathrm{D}$ distance from the object to the walls, resulting in a thickness of $8 D$. This is necessary for the development of vortices and to capture relevant information of the flow (velocity and pressure).

\subsection{Mesh}

In this step, the computational domain is refined following the criteria of the element type, local grid refinement, element quality, and mesh quality.

\subsection{Boundary conditions}

Prescribed boundary conditions are given by (i) pressure and velocity at the inlet and outlet, (ii) zero normal velocity (no-slip condition) for structural boundary and ground, (iii) free to slide condition for the remaining boundaries. A general scheme is presented in Figure 5.

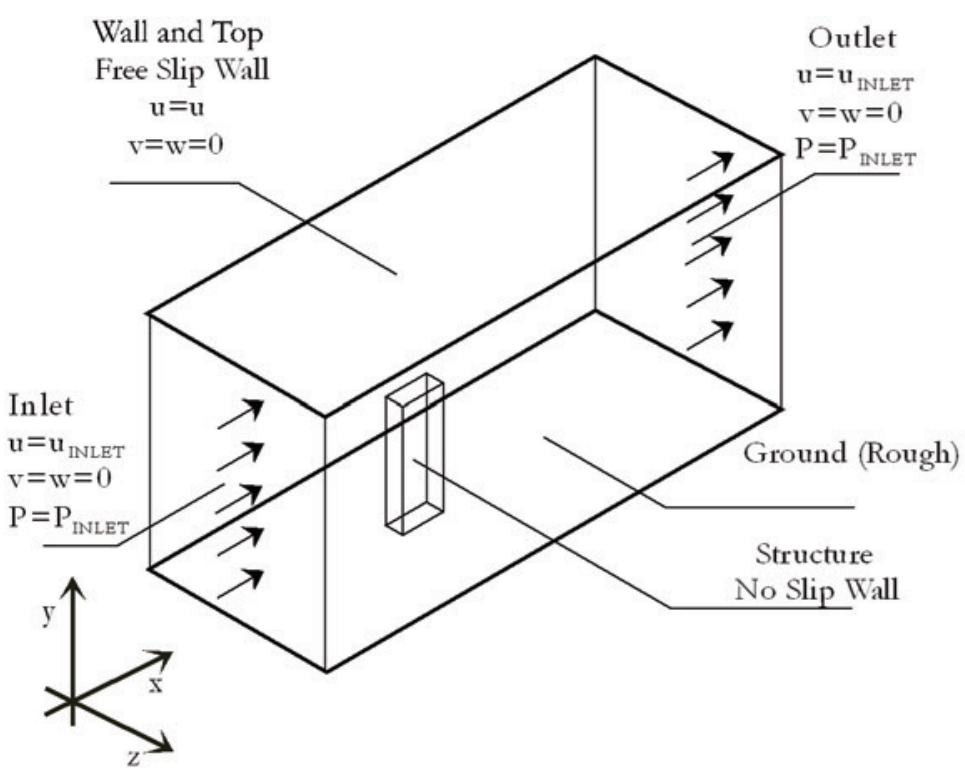

(a) Wind tunnel numerical
Inlet

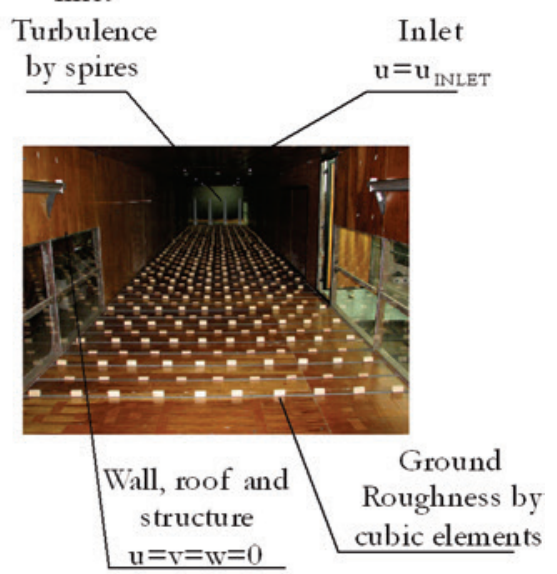

(b) Wind tunnel experimental

Figure 5

Boundary conditions 


\subsubsection{Inlet}

The input face is selected and the wind speed at the inlet is considered. To insert the velocity, two main methods are highlighted. The first is to consider speed input as a function of height ( $Z$ ), according to the logarithmic law in equation (6), with $\mathrm{u}_{+}$defined by $\sqrt{\tau / \rho}$.

$\frac{V}{u_{+}}=\frac{1}{k} \ln \left(\frac{Z}{Z_{0}}\right)$

Another possible strategy, resembling wind tunnel tests, is to apply constant speed at the inlet. In this way ground roughness causes the speed profile to develop naturally. However, when using this method, two essential points should be emphasized: the mesh refinement in the floor and the size of the upstream and downstream computational domains must be large enough to capture flow effects.

\subsubsection{Outlet}

At the outlet, it is possible to define speed or pressure (gauge or atmospheric). In practice, the outer pressure is prescribed, allowing velocity to be developed naturally along the domain.

\subsubsection{Wall and ceiling (top wall)}

On walls (side faces) and ceiling (top face) it is admitted that the fluid is free to flow.

\subsubsection{Ground and structure}

Simulations of structures located far from the ground (Figure 4a), such as aqueducts and bridges allow considering the floor as freeslip wall condition. However, for ground-based structures, as is the case of buildings, the no-slip condition must be considered, and the roughness of the floor must be specified. This parameter is calibrated from speed profiles or design values.

Depending on the design, the roughness of the structure should be considered, however additional studies must be performed in this case. Due to the surface finish of the structures applied in this work, the roughness of the object walls could be neglected. In this way, the no-slip condition was adopted in these models.

\subsection{Turbulence model}

A RANS turbulence model, described in section 2, is selected based on two criteria for a selected global variable: (i) smaller amplitudes over time and (ii) greater proximity to the theoretical value on the numerical prototype. Models with large amplitudes should be avoided, even if their mean value is close to the theoretical one, because, at a given stopping point of the simulation, peak values may not represent the global variable. To perform these simulations, an intermediate mesh is employed, avoiding high computational costs. Therefore, no more than 50,000 nodes for the two-dimensional flow and 200,000 nodes in the three-dimensional case are sufficient at this preliminary stage.

\subsection{Convergence studies}

In a broad sense, convergence on this proposal is based on asymptotic curves tending to a number (Lewis et al. [28]), providing mesh independence in time, number of iterations and space. The numerical model is said to be convergent when average values of the selected global variable remain approximately constant over time.

\subsubsection{Independence of time}

The numerical model is submitted to studies in the transient regime using the following criteria: (i) total time of flow simulation and (ii) time step. The duration of the flow should be such that the fluid crosses ' $n$ ' times the domain, where ' $n$ ' should be enough for the stabilization of the global variable. The time step is selected based on the Courant number:

Courant $=\frac{u \Delta x}{\Delta t}$

For solvers with implicit schemes, it is possible for the Courant number to be greater than 1 . In the absence of an initial estimate, it is pointed out the need for a convergence analysis of this variable,

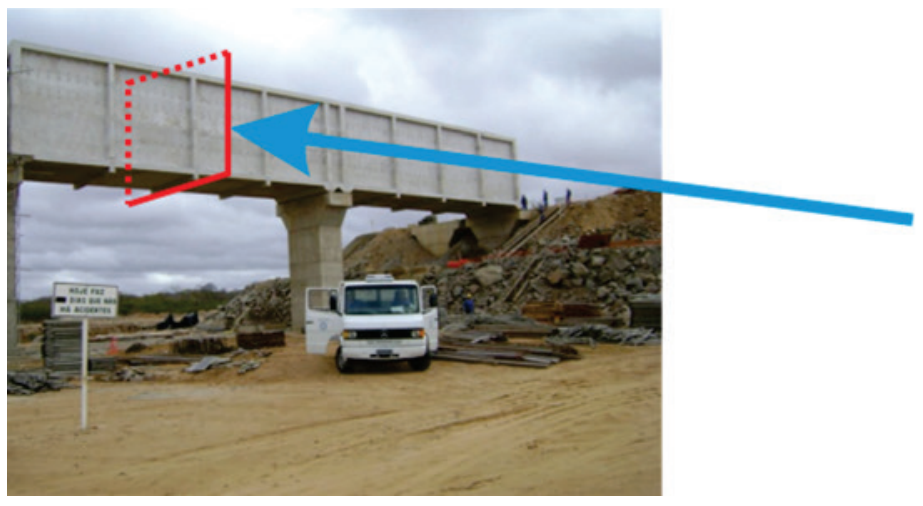

(a) Aquedut

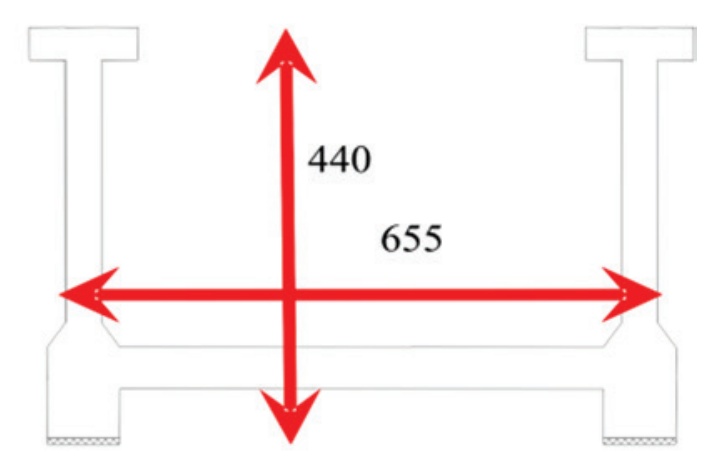

(b) Cross section

Figure 6

Concrete aqueduct details (units in centimeter) 


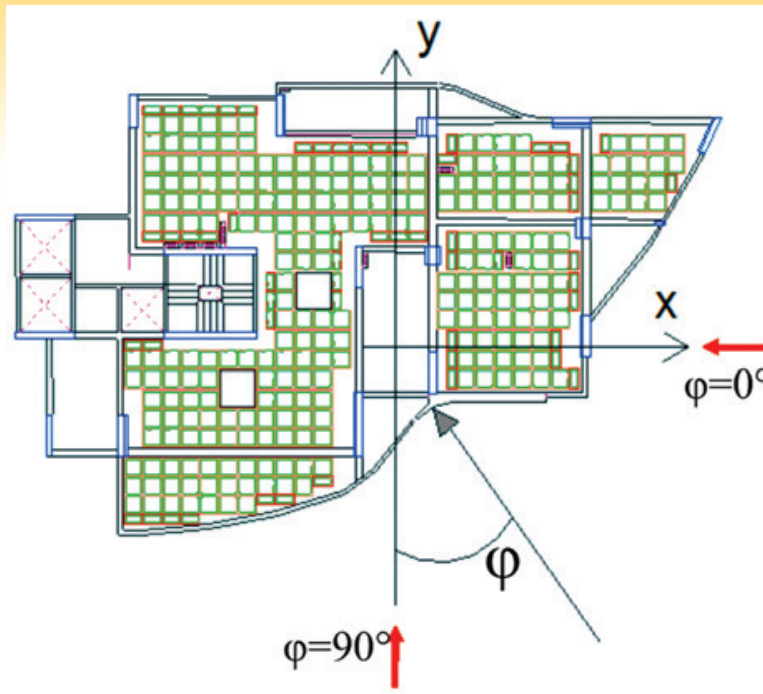

(a) Floor plan and wind incidence angle $\varphi$

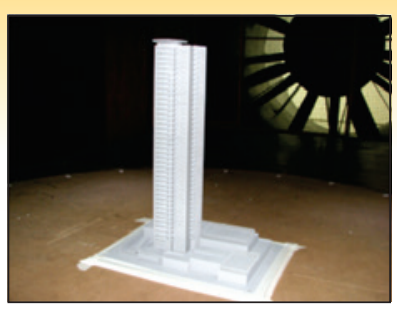

(b) Wind tunnel test model

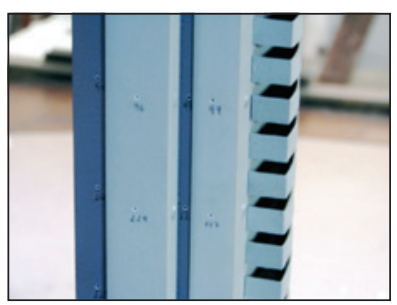

(d) Pressure sensors

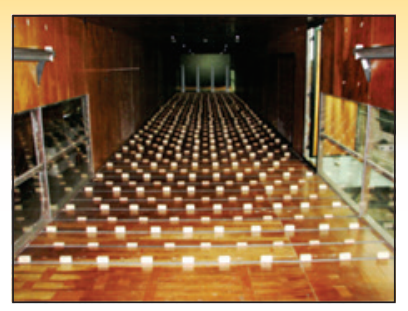

(c) Ground roughness detail

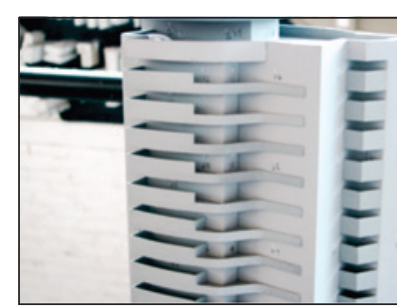

(e) Building details

\section{Figure 7}

Wind tunnel test and details (Model 04) (IPT [8])

using different time steps. In this convergence study, an upper bound must be verified for this parameter, so that time independence is achieved for the flow.

A point to be highlighted is that equation 7 shows the relation between temporal and spatial domains. Thus, in reducing element sizes, time step values should also be reduced, guaranteeing the same Courant number. The authors point out that this will increase mesh complexity and simulation costs, making the numerical model infeasible on average computers.

\subsubsection{Number of iterations}

Another variable in CFD is the number of iterations that are performed in each time step, where linearization of the non-linear terms of the Navier-Stokes equations is performed. Since this parameter influences computational cost, a convergence study must be made. For a given mesh, the number of iterations must range from 1 to 50 , providing the smallest value for a global parameter estimate at the lowest computational cost.

\subsubsection{Simulation stop criteria}

The total simulation time is selected so that the global variable exhibits cyclic behavior, with the mean result providing agreement with reference values. This is necessary for stabilization of the global variable and validation of the numerical prototype.

\subsubsection{Independence of space}

Mesh convergence study is performed by reducing element size, thus verifying the behavior of the global variable as the number of elements increases. In turbulent flows, mesh improvement may cause the appearance of localized phenomena, initially not present. This spatial criterion guarantees the accuracy of the computational model.

\subsubsection{Final model - real structure}

The evaluation of a real structure arises after calibration of a numerical prototype. Thus, turbulence models, convergence criteria and computational domain, among others, are applied or adapted

to the final model. This procedure allows a progressive evolution to the simulation of a real structure, where theoretical or experimental values are unknown. Figure 3 illustrates this procedure.

On this paper, two numerical prototypes (square section and cube, models 01 and 02) were selected for simulation of real structures, exemplified by an aqueduct and a building (models 03 and 04). These will be analyzed in the next section.

\section{Implementation of the proposed procedures in concrete structures: study of aqueduct and high-rise building}

Simulations were performed using Ansys v.14.0[29] with its computational fluid module CFX. This module implicitly solves the nonlinear system of equations described in Section 1 for pressure and flow velocity in space and time, through the finite volume method. Mesh refinements were performed with tetrahedral or hexahedral elements. Simplifications in structural geometry were necessary to reduce computational cost. Hardware features include a desktop PC with quad-core processor Intel i $^{7}$ - 4770 , 3.40GHz, 8.00GB RAM memory, 64-bit operating system.Simulations were initially performed for numerical prototypes according to Figure 3 (models 1 and 2). In a sequence, the real models were studied (models 3 and 4 ).

In structures like aqueducts or bridges (Figure 6), where one dimension prevails over the other and velocity profile along the longitudinal length is substantially constant, it is possible to approach the drag value to a section cut (two-dimensional). Therefore, the geometry of the aqueduct (model 03 ) is defined by a $U$ section, as indicated in Figure $6 \mathrm{~b}$. This cross-section will be simplified to a rectangle with dimensions of $655 \times 440 \mathrm{~cm}$. For this section, a theoretical drag coefficient is $C_{D}=1.95$ (with linear interpolation; provided by Çengel and Cimbala [30]).

Model 04 simulates a reinforced concrete building of 40 floors $(130.30 \mathrm{~m})$. The geometry of this structure is shown in Figure 7a, along with the floor plan and the wind incidence angle. In this work, only winds with $\varphi=0^{\circ}$ and $\varphi=90^{\circ}$ are analyzed, knowing that the methodology will be the same for any other angle $\varphi$.

Reference values for Model 04 were obtained from an experimental test with a 1:200 scale model (Figure7b-e), conducted in the 
From numerical prototypes to real models: a progressive study of aerodynamic parameters of nonconventional concrete structures with Computational Fluid Dynamics

\section{Table 2}

Simulations parameter - aqueduct and building

\begin{tabular}{|c|c|c|c|}
\hline \multicolumn{2}{|c|}{ Parameter } & Model 03 & Model 04 \\
\hline \multirow{4}{*}{ Air } & \multirow{3}{*}{$\begin{array}{c}\text { Temperature } \\
\rho \\
\mu\end{array}$} & \multicolumn{2}{|c|}{$25^{\circ} \mathrm{C}$} \\
\hline & & \multirow{2}{*}{\multicolumn{2}{|c|}{$\begin{array}{c}1.185 \mathrm{~kg} / \mathrm{m}^{3} \\
1.831 \times 10^{5} \mathrm{~kg} / \mathrm{ms}\end{array}$}} \\
\hline & & & \\
\hline & \multirow[t]{2}{*}{ Velocity inlet } & $30 \mathrm{~m} / \mathrm{s}(108 \mathrm{~km} / \mathrm{h})$ & $30 \mathrm{~m} / \mathrm{s}(108 \mathrm{~km} / \mathrm{h})$ \\
\hline Reynold & & $7.2 \times 10^{6}$ & $\begin{array}{l}3.9 \times 10^{\circ} \text { in } \varphi=0^{\circ} \\
5.8 \times 10^{\circ} \text { in } \varphi=90^{\circ}\end{array}$ \\
\hline \multicolumn{2}{|c|}{ Element type } & Hexahedral & Tetrahedral \\
\hline \multicolumn{2}{|c|}{ Pressure outlet } & $\mathrm{OPa}$ & $\mathrm{OPa}$ \\
\hline \multirow{2}{*}{ Wall conditions } & Free-slip wall & Top, bottom and sides & Top and sides \\
\hline & No slip wall & Structure & Structure and bottom \\
\hline \multicolumn{2}{|c|}{ Turbulence model } & $k-\varepsilon$ & SST \\
\hline \multicolumn{2}{|c|}{ Total simulation time } & 10s & 20 s \\
\hline \multicolumn{2}{|c|}{ Courant number } & \multicolumn{2}{|c|}{ Between 10 and 20} \\
\hline \multicolumn{2}{|c|}{ Number of interactions } & 10 & 10 \\
\hline \multicolumn{2}{|c|}{ Roughness } & 0 & $0.32 \mathrm{~m}$ \\
\hline \multicolumn{2}{|c|}{ RMS } & $10^{10}$ & $10^{10}$ \\
\hline
\end{tabular}

Atmospheric Boundary Wind Tunnel of the Technological Research Institute (IPT [8]). Force values on each floor were computed by means of 285 pressure sensors (Figure $7 d$ ).

Numerical simulations required some adjustments to produce a feasible computational model. In this way, rooftop elements (helipad, water tank, among others) and ground level floor details were neglected. This simplified model has 40 identical floors ranging from 0 to $130.30 \mathrm{~m}$ elevation.

Table 2 describes the main parameters adopted in the simulations. The Courant number, turbulence model, number of interactions and RMS (root mean square) were obtained with a numerical prototype, and its details are presented in the next sections.

\subsection{Geometry}

Details of the geometric domain are given in Figure 8. Transition regions were prescribed for mesh refinement according to Section 4.1. A scale factor 1:10 was adopted for the real building (model 4), only as a verification of the scale analysis, assuming that the software will perform mathematical operations and such a strategy will not lead to errors in the simulation.

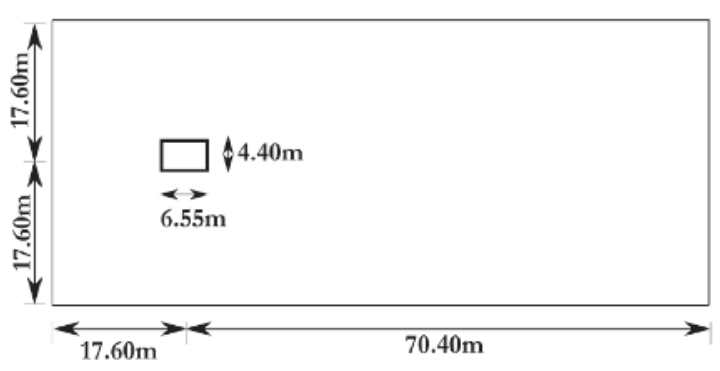

(a) Aqueduct domain

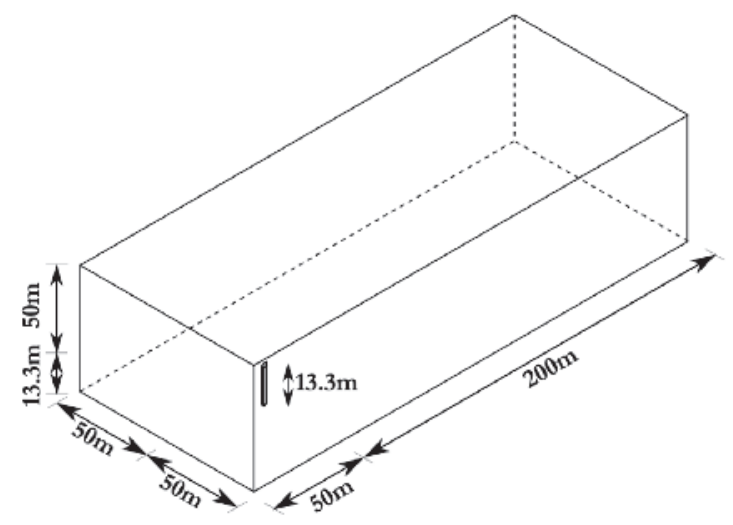

(c) Building domain

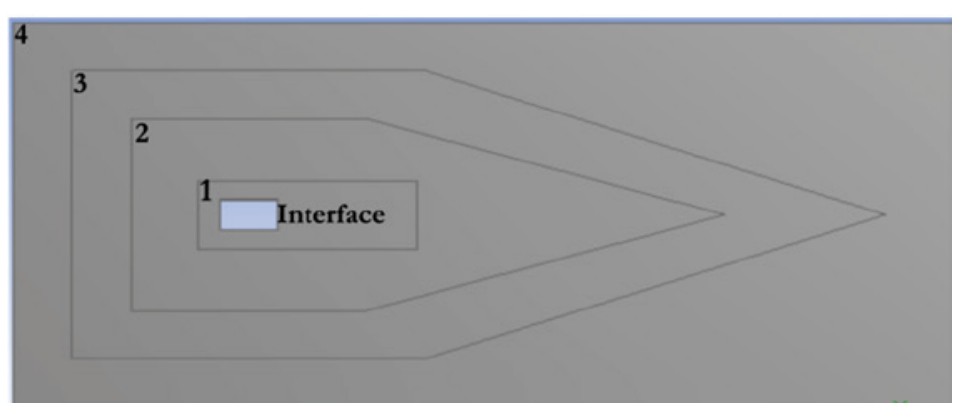

(b) Aqueduct subdomain

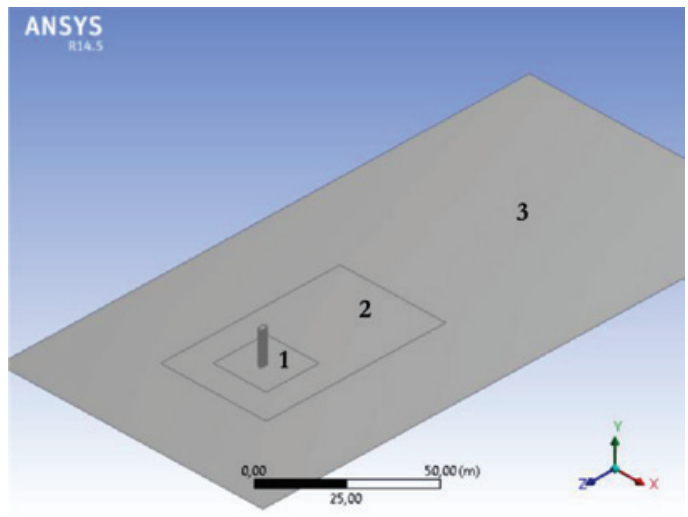

(d) Building subdomain

Figure 8

Domains and subdomains 
Table 3

Mesh refinement - element size in meters $(m)$

\begin{tabular}{|c|c|c|c|c|c|c|}
\hline & Subdomain & Mesh 01 & Mesh 02 & Mesh 03 & Mesh 04 & Mesh 05 \\
\hline \multirow{6}{*}{$\begin{array}{l}\frac{0}{0} \\
\frac{0}{0} \\
\frac{\varnothing}{2}\end{array}$} & 1 & $\mathrm{D}$ & $0.2 \mathrm{D}$ & $0.1 \mathrm{D}$ & $0.05 \mathrm{D}$ & $0.02 \mathrm{D}$ \\
\hline & 2 & $2 \mathrm{D}$ & $0.4 \mathrm{D}$ & $0.2 \mathrm{D}$ & $0.1 \mathrm{D}$ & $0.05 \mathrm{D}$ \\
\hline & 3 & $4 \mathrm{D}$ & $0.8 \mathrm{D}$ & $0.4 \mathrm{D}$ & $0.2 \mathrm{D}$ & $0.1 \mathrm{D}$ \\
\hline & 4 & $8 \mathrm{D}$ & $1.6 \mathrm{D}$ & $0.8 \mathrm{D}$ & $0.4 \mathrm{D}$ & $0.2 \mathrm{D}$ \\
\hline & \multicolumn{6}{|c|}{ Number of nodes } \\
\hline & Aqueduct & 3,042 & 10,551 & 20,665 & 47,727 & 178,043 \\
\hline \multirow{7}{*}{$\begin{array}{l}\frac{\square}{0} \\
\frac{0}{0} \\
\frac{0}{\Sigma}\end{array}$} & Subdomain & Mesh 01 & Mesh 02 & Mesh 03 & Mesh 04 & Mesh 05 \\
\hline & 1 & $\mathrm{D}$ & $0.5 \mathrm{D}$ & $0.25 \mathrm{D}$ & $0.125 \mathrm{D}$ & $0.0625 \mathrm{D}$ \\
\hline & 2 & $2 \mathrm{D}$ & D & $0.5 \mathrm{D}$ & $0.25 \mathrm{D}$ & $0.125 \mathrm{D}$ \\
\hline & 3 & $4 \mathrm{D}$ & $2 \mathrm{D}$ & D & $0.5 \mathrm{D}$ & $0.25 \mathrm{D}$ \\
\hline & Interface & $0.1 \mathrm{D}$ & $0.05 \mathrm{D}$ & $0.025 \mathrm{D}$ & $0.0125 \mathrm{D}$ & $0.00625 \mathrm{D}$ \\
\hline & \multicolumn{6}{|c|}{ Number of nodes } \\
\hline & Building & 23,212 & 32,656 & 56,264 & 203,282 & 658,007 \\
\hline
\end{tabular}
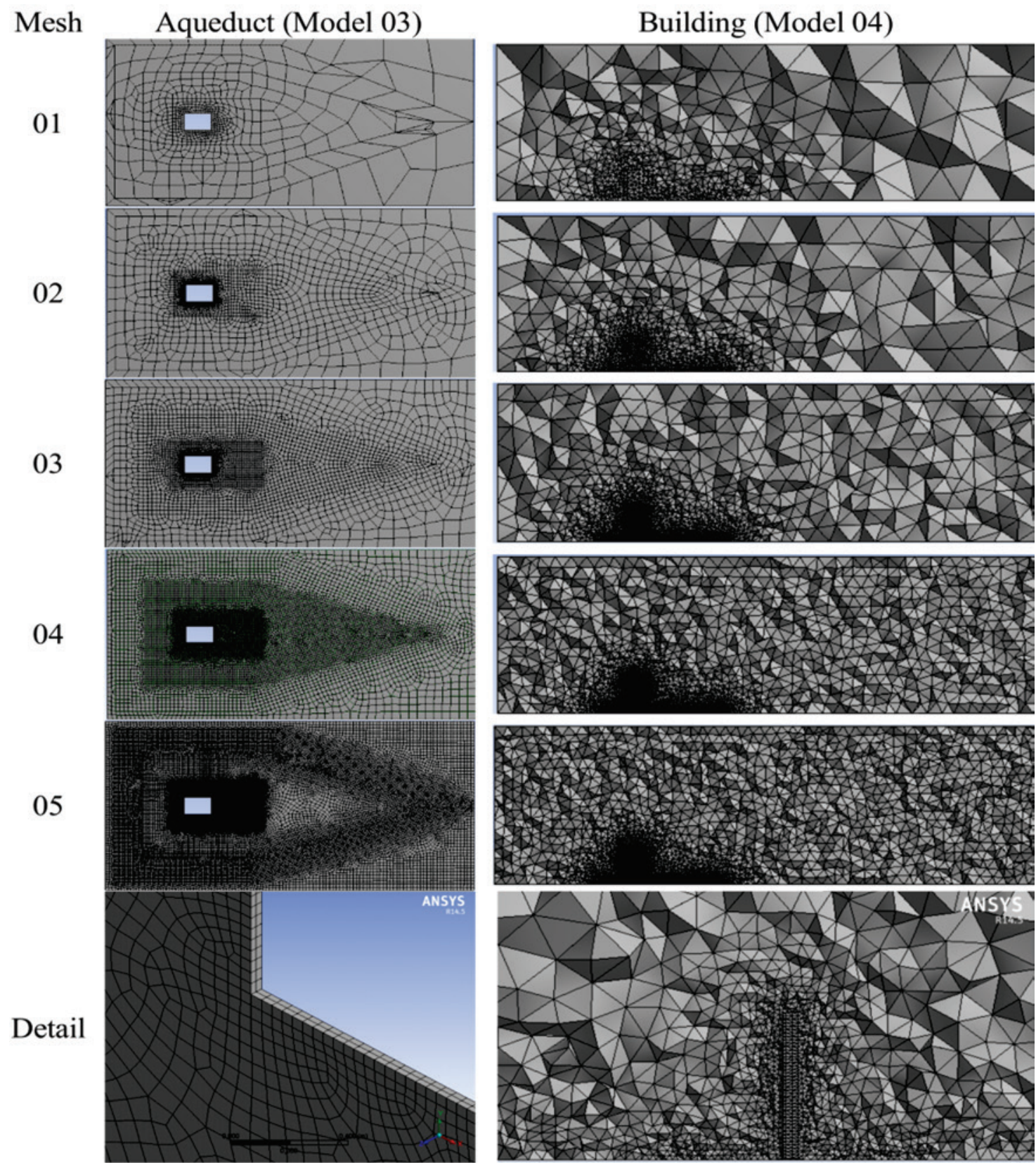

\section{Figure 9}

Mesh refinement details 


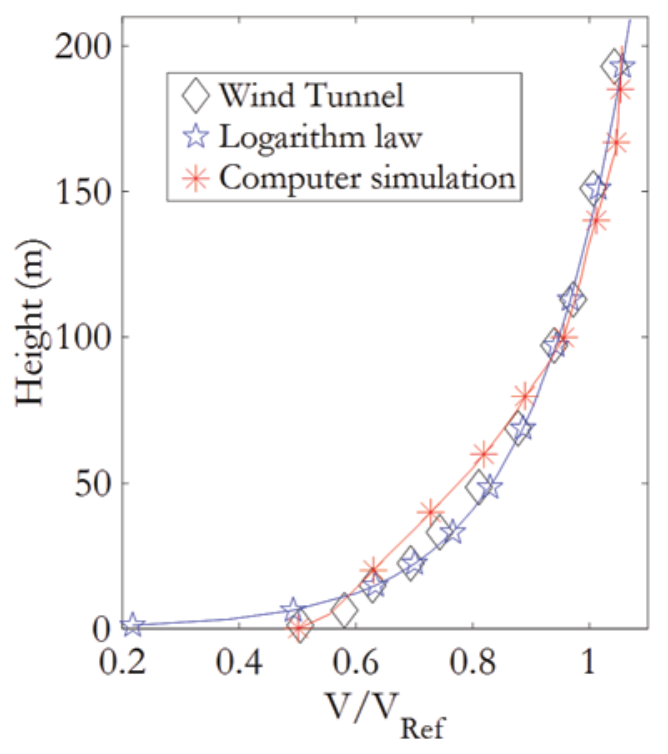

Figure 10

Velocity profile - Model 04

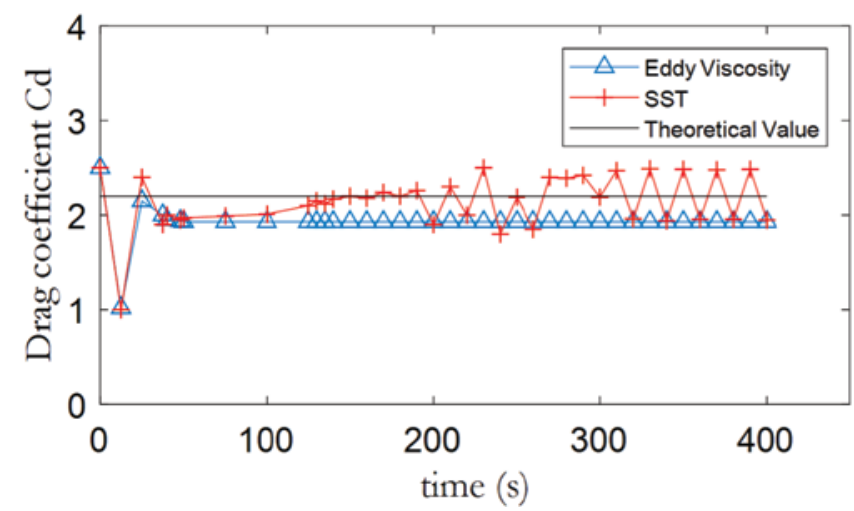

\subsection{Computational mesh}

\subsubsection{Domain refinement}

Due to the high computational cost, the use of small volumes in the entire computational domain is avoided. However, specific regions, such as the boundary layer and wake, require localized refinement to capture flow relevant effects. Figure $4 b$ shows a proposal for subdomains where the smallest element sizes are located near the structure. Transition regions are required, enabling progressive refinement towards the center. A total of five computational meshes were employed for each model. Element size was selected based on the characteristic dimension of the structure, with $D=4.40 \mathrm{~m}$ for Model 03 and $D=2.00 \mathrm{~m}$ for Model $04(20.0 \mathrm{~m}$ in a real building without scale factor). Additional mesh parameters and details are given in Table 3 and Figure 9. The meshes must be generated for elements with aspect ratio and orthogonality close to 1 (one) and skewness close to 0 (zero). The use of conforming meshes is recommended. Mesh quality criteria were verified in both models, focused on low-quality elements only in regions that are not very sensitive to the flow.

\section{Figure 11}

Convergence of test of different turbulence models - square section (Model 1)
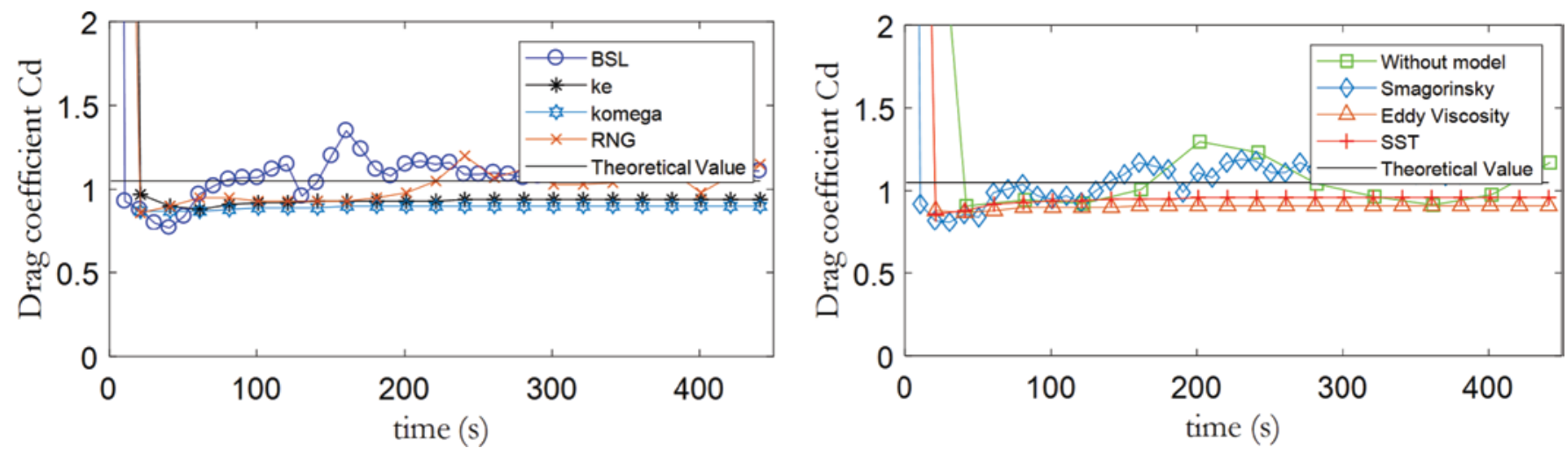

Figure 12

Convergence test of different turbulence models - cube (Model 2) 
Table 4

Mean drag coefficients for different turbulence models (Models 1 and 2)

\begin{tabular}{|c|c|c|c|c|c|c|c|c|c|c|c|}
\hline & SST & RNG & SSG & $\begin{array}{l}\text { Whitout } \\
\text { model }\end{array}$ & $\mathrm{k}-\omega$ & BSL & $\mathrm{k}-\varepsilon$ & Smagorinsky & $\begin{array}{c}\text { Eddy } \\
\text { viscosity }\end{array}$ & $\begin{array}{c}\text { Theoretical } \\
\text { value }\end{array}$ & Average \\
\hline Square & 2.14 & 2.44 & 2.27 & - & 1.91 & - & 2.01 & - & 1.93 & 2.20 & 2.00 \\
\hline Cube & 0.95 & 1.04 & - & 1.05 & 0.90 & 1.11 & 0.94 & 1.08 & 0.91 & 1.05 & 1.00 \\
\hline
\end{tabular}

\subsection{Boundary conditions}

For Model 03 , wind velocity was prescribed according to design data(IPT [8]). In Model 04, it was considered as $30 \mathrm{~m} / \mathrm{s}$, which is the reference value on the wind tunnel report. In this last case, wind speed acting on the structure is presented by Figure 10 using three different approaches: (i) wind tunnel test results, (ii) equation (6) with parameters given by $u_{+} 0.97 \mathrm{~m} / \mathrm{s}$;

$\mathrm{k}=0.40$ and $\mathrm{Z}=0.32 \mathrm{~m}$, (iii) computational simulation. The selected roughness value provides a good agreement with experimental or theoretical results. Remaining boundary conditions (floor and walls) are given in Table 2.

\subsection{Turbulence model}

A study of the turbulence models described in Section 2 was carried out to verify which of these models best represents the target parameter (experimental or literature values for the drag coefficient). These analyses were performed on the numerical prototypes (square section and cube) shown in Figure 11 and Figure 12. A list of mean drag coefficient values is summarized in Table 4. For Model 1 (square section) most of the mean values are in agreement with the theoretical reference $\left(C_{D}=2.2\right)$, with relative errors at a maximum of $12 \%$. For model 2 (cube section) the maximum relative error is given by $10 \%$. Therefore, it is concluded that in terms of the mean values for the drag coefficient, any turbulence model will provide a good estimate when compared to the reference value. On the other hand, some of the models may exhibit varying amplitudes, which are of secondary nature, since only mean values are required for drag force computations in real structures. For the real structures, $k-\varepsilon$ and SST turbulence models were selected for the aqueduct and high-rise building, respectively.

\subsection{Convergence}

\subsubsection{Temporal discretization}

A Courant number convergence test was performed for reference models 01 and 02 . Values in the range $10-20$ resulted in satisfactory results. The flow duration was defined as 3 times the time required for the fluid to flow the entire domain.

\subsubsection{Number of iterations}

In the numerical prototypes, a number of iterations over 10 per time step resulted in a good agreement with theoretical values. Therefore, this value was selected for Models 03 and 04 .

\subsubsection{Independence of space}

Computational meshes were studied according to the refinement provided by Table 3. Figure 13 shows the mesh convergence analysis for Model 03.

In Model 04, simulations were performed for two incidence angles, where several data were computed. Among them: global drag and average force on each floor. Figure 14 illustrates mesh independence studies of this model on floors 25 , wind at $90^{\circ}$. The remaining floors were also verified, showing similar behavior.

\subsection{Results}

The numerical models obtained after application of the proposed procedure are the best estimate of the real scenario. For validation, these results were compared to experimental or theoretical values.

\subsubsection{Aqueduct}

Figure 13 presented the converged drag coefficient value for the aqueduct $\left(C_{D}=1.93\right)$, where the simulation error for the last mesh was $1.03 \%$ and the processing time was $40.8 \mathrm{~h}$.

\subsubsection{High-rise building}

From the simulations carried out in the high-rise building, Table 5 was elaborated for analysis on each floor for the $0^{\circ}$ and $90^{\circ}$ incidence angles.

The error was calculated considering the wind tunnel test results

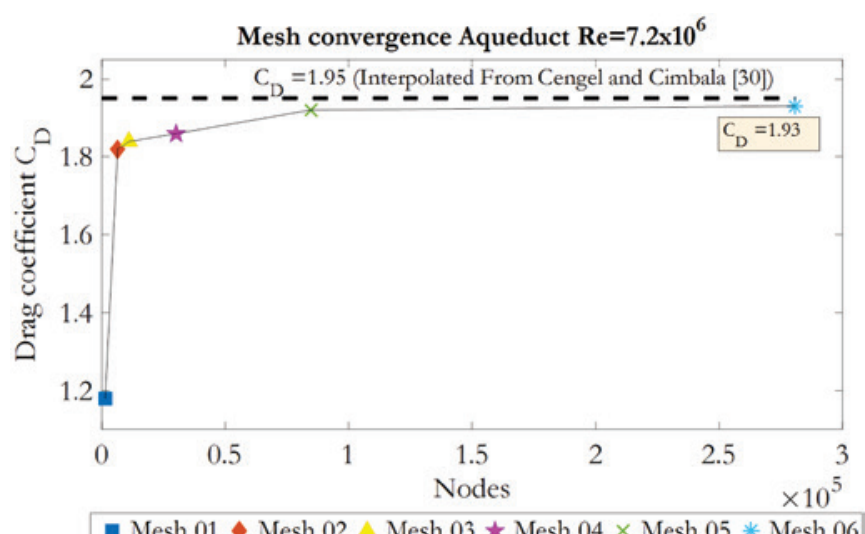

Figure 13

Mesh convergence - average drag - Model 03 
as a reference. In this table, besides the errors per floor, it is also indicated if the value of the computational simulation was superior or inferior to the experimental one (arrows), verifying that there is no pattern in the whole floor, that is, the CFD was not always an upper or lower estimate when compared to the experimental results. In Figure 15, it can be verified that the largest errors are in the floors that were neglected in modeling: upper and lower level. This figure is a global analysis, verifying the sum of the forces in the whole build- ing for each incidence angle, allowing to quantify the global error and verify the force distribution along the structural height.

It is possible to summarize the simulations from the values obtained for the drag coefficients. Table 6 presents these results.

The average time required to perform the methodology for a given discretization (mesh 04) is shown in Table 7. It is known that this time is only an estimate since it depends on the complexity of the geometry and boundary conditions.

\section{Table 5}

Wind force resultant - incident angles at $0^{\circ}$ and $90^{\circ}$

\begin{tabular}{|c|c|c|c|c|c|c|c|}
\hline \multirow[b]{2}{*}{ Floor } & \multirow[b]{2}{*}{ Height-z (m) } & \multicolumn{2}{|c|}{ Force $(\mathrm{N})$ at $0^{\circ}$} & \multicolumn{2}{|c|}{ Force $(\mathrm{N})$ at $90^{\circ}$} & \multirow{2}{*}{$\begin{array}{l}\text { Error (\%) } \\
\text { wind at } 0^{\circ}\end{array}$} & \multirow{2}{*}{$\begin{array}{c}\text { Error (\%) } \\
\text { wind at } 90\end{array}$} \\
\hline & & Wind tunnel & $\begin{array}{l}\text { Computer } \\
\text { simulation }\end{array}$ & Wind Tunnel & $\begin{array}{l}\text { Computer } \\
\text { simulation }\end{array}$ & & \\
\hline 1 & 13.3 & $32,678.0$ & $34,396.0$ & $11,659.9$ & $17,697.8$ & $5.3 \uparrow$ & $51.8 \uparrow$ \\
\hline 2 & 16.3 & $33,927.6$ & $34,965.5$ & $11,659.9$ & $17,764.6$ & $3.1 \uparrow$ & $52.4 \uparrow$ \\
\hline 3 & 19.3 & $33,179.8$ & $35,251.8$ & $13,120.3$ & $17,701.6$ & $6.2 \uparrow$ & $34.9 \uparrow$ \\
\hline 4 & 22.3 & $32,258.5$ & $35,511.7$ & $14,398.0$ & $17,557.8$ & $10.1 \uparrow$ & $21.9 \uparrow$ \\
\hline 5 & 25.3 & $32,677.9$ & $35,806.2$ & $14,398.0$ & $17,213.4$ & $9.6 \uparrow$ & $19.6 \uparrow$ \\
\hline 6 & 28.3 & $32,349.2$ & $35,713.6$ & $14,558.1$ & $17,119.3$ & $10.4 \uparrow$ & $17.6 \uparrow$ \\
\hline 7 & 31.3 & $31,847.3$ & $35,816.6$ & $14,741.1$ & $17,105.5$ & $12.5 \uparrow$ & $16.0 \uparrow$ \\
\hline 8 & 34.3 & $30,570.4$ & $35,794.9$ & $14,741.1$ & $16,648.8$ & $17.1 \uparrow$ & $12.9 \uparrow$ \\
\hline 9 & 37.3 & $31,148.2$ & $35,746.6$ & $15,202.7$ & $16,685.6$ & $14.8 \uparrow$ & $9.8 \uparrow$ \\
\hline 10 & 40.3 & $32,068.4$ & $35,623.0$ & $15,895.1$ & $16,682.9$ & $11.1 \uparrow$ & $5.0 \uparrow$ \\
\hline 11 & 43.3 & $31,769.1$ & $35,953.1$ & $15,895.1$ & $16,398.6$ & $13.1 \uparrow$ & $3.2 \uparrow$ \\
\hline 12 & 46.3 & $32,167.3$ & $35,817.4$ & $16,087.6$ & $16,172.2$ & $11.4 \uparrow$ & $0.5 \uparrow$ \\
\hline 13 & 49.3 & $32,660.9$ & $35,957.9$ & $16,472.7$ & $16,348.8$ & $10.1 \uparrow$ & $0.8 \downarrow$ \\
\hline 14 & 52.3 & $32,887.2$ & $36,113.9$ & $16,472.7$ & $16,074.2$ & $9.8 \uparrow$ & $2.4 \downarrow$ \\
\hline 15 & 55.3 & $33,392.6$ & $35,991.9$ & $16,632.4$ & $16,083.3$ & $7.8 \uparrow$ & $3.3 \downarrow$ \\
\hline 16 & 58.3 & $34,165.7$ & $36,030.8$ & $17,071.6$ & $16,180.2$ & $5.5 \uparrow$ & $5.2 \downarrow$ \\
\hline 17 & 61.3 & $34,402.9$ & $35,917.6$ & $17,071.6$ & $16,393.5$ & $4.4 \uparrow$ & $4.0 \downarrow$ \\
\hline 18 & 64.3 & $34,839.2$ & $35,853.2$ & $17,221.3$ & $16,937.2$ & $2.9 \uparrow$ & $1.6 \downarrow$ \\
\hline 19 & 67.3 & $35,901.3$ & $35,760.5$ & $17,820.2$ & $17,060.3$ & $0.4 \downarrow$ & $4.3 \downarrow$ \\
\hline 20 & 70.3 & $36,094.2$ & $35,829.2$ & $17,820.2$ & $17,268.8$ & $0.7 \downarrow$ & $3.1 \downarrow$ \\
\hline 21 & 73.3 & $36,334.1$ & $36,025.3$ & $17,932.0$ & $16,740.1$ & $0.9 \downarrow$ & $6.6 \downarrow$ \\
\hline 22 & 76.3 & $37,390.0$ & $36,070.5$ & $18,658.6$ & $16,517.6$ & $3.5 \downarrow$ & $11.5 \downarrow$ \\
\hline 23 & 79.3 & $37,642.5$ & $36,252.9$ & $18,658.6$ & $16,787.5$ & $3.7 \downarrow$ & $10.0 \downarrow$ \\
\hline 24 & 82.3 & $37,736.2$ & $36,571.2$ & $18,708.3$ & $16,903.9$ & $3.1 \downarrow$ & $9.6 \downarrow$ \\
\hline 25 & 85.3 & $38,453.7$ & $37,153.3$ & $19,404.3$ & $17,023.5$ & $3.4 \downarrow$ & $12.3 \downarrow$ \\
\hline 26 & 88.3 & $38,730.3$ & $37,715.5$ & $19,404.3$ & $17,621.5$ & $2.6 \downarrow$ & $9.2 \downarrow$ \\
\hline 27 & 91.3 & $38,999.8$ & $38,604.0$ & $19,404.3$ & $18,332.5$ & $1.0 \downarrow$ & $5.5 \downarrow$ \\
\hline 28 & 94.3 & $40,014.1$ & $39,582.6$ & $19,750.7$ & $18,338.1$ & $1.1 \downarrow$ & $7.2 \downarrow$ \\
\hline 29 & 97.3 & $40,354.2$ & $40,770.9$ & $19,750.7$ & $18,059.1$ & $1.0 \uparrow$ & $8.6 \downarrow$ \\
\hline 30 & 100.3 & $40,438.2$ & $42,120.0$ & $19,750.7$ & $18,872.8$ & $4.2 \uparrow$ & $4.4 \downarrow$ \\
\hline 31 & 103.3 & $41,894.0$ & $43,444.9$ & $20,125.2$ & $17,762.0$ & $3.7 \uparrow$ & $11.7 \downarrow$ \\
\hline 32 & 106.3 & $42,359.6$ & $44,842.5$ & $20,151.9$ & $18,196.2$ & $5.7 \uparrow$ & $9.7 \downarrow$ \\
\hline 33 & 109.3 & $42,555.2$ & $46,099.2$ & $20,151.9$ & $17,948.9$ & $8.3 \uparrow$ & $10.9 \downarrow$ \\
\hline 34 & 112.3 & $43,462.6$ & $47,072.3$ & $20,835.4$ & $17,543.8$ & $8.3 \uparrow$ & $15.8 \downarrow$ \\
\hline 35 & 115.3 & $43,768.3$ & $47,874.4$ & $20,940.5$ & $17,405.1$ & $9.4 \uparrow$ & $16.9 \downarrow$ \\
\hline 36 & 118.3 & $44,063.9$ & $48,214.2$ & $20,940.5$ & $17,216.1$ & $9.4 \uparrow$ & $17.8 \downarrow$ \\
\hline 37 & 121.3 & $44,552.7$ & $48,580.9$ & $21,394.8$ & $17,041.3$ & $9.1 \uparrow$ & $20.3 \downarrow$ \\
\hline 38 & 124.3 & $44,868.9$ & $47,900.1$ & $21,507.9$ & $16,739.1$ & $6.8 \uparrow$ & $22.2 \downarrow$ \\
\hline 39 & 127.3 & $44,676.7$ & $45,863.7$ & $21,507.9$ & $14,715.0$ & $2.7 \uparrow$ & $31.6 \downarrow$ \\
\hline 40 & 130.3 & $21,445.4$ & $30,355.5$ & $10,484.2$ & $8,781.6$ & $41.5 \uparrow$ & $16.2 \downarrow$ \\
\hline \multicolumn{2}{|c|}{ Global } & $1,460,726$ & $1,544,965$ & 698,402 & 675,640 & $5.77 \uparrow$ & $3.37 \downarrow$ \\
\hline
\end{tabular}



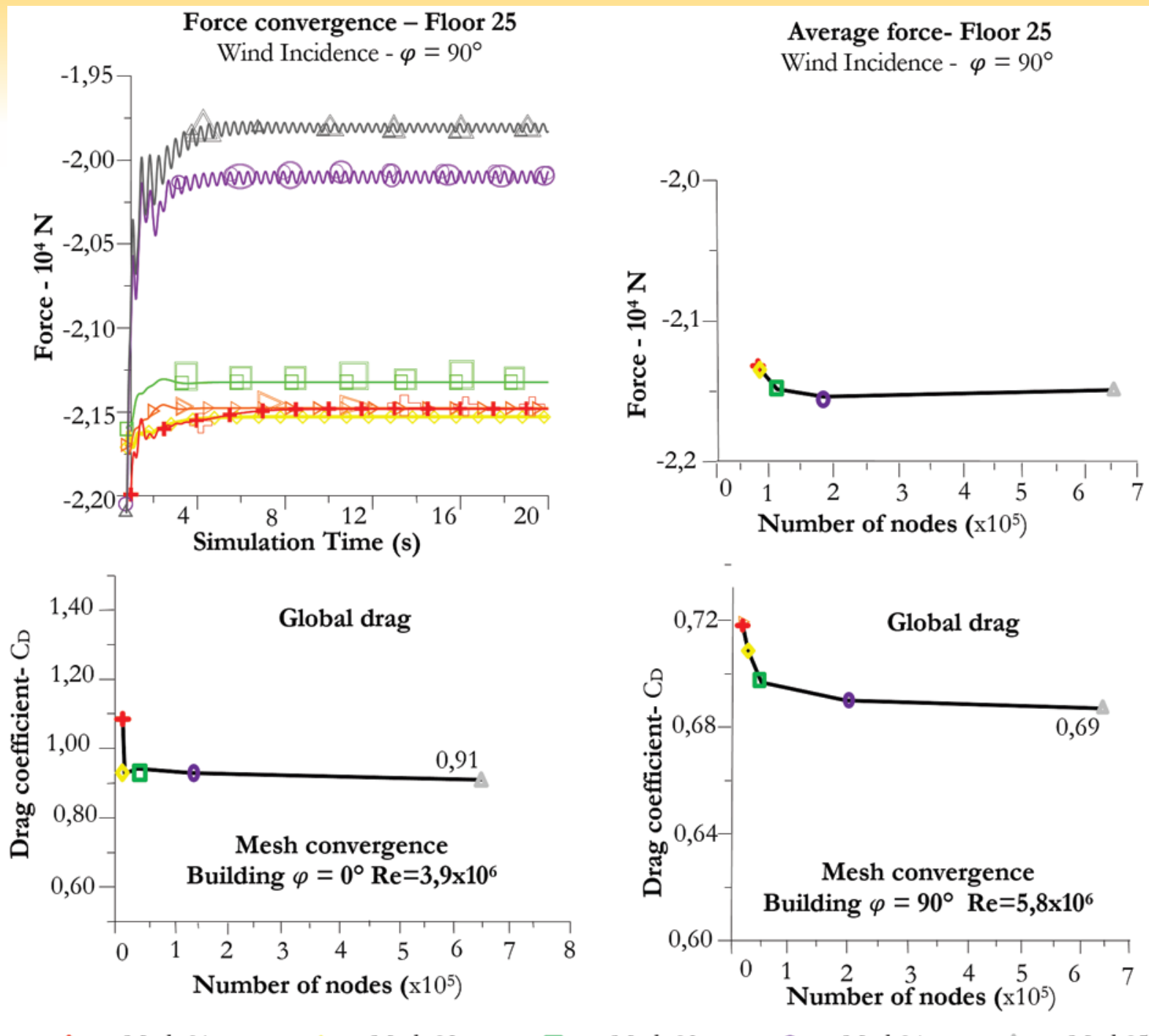

$+\quad$ Mesh 01

Mesh 02

Mesh 03

- Mesh04

$\triangle \quad$ Mesh05

\section{Figure 14}

Mesh convergence - Model 04
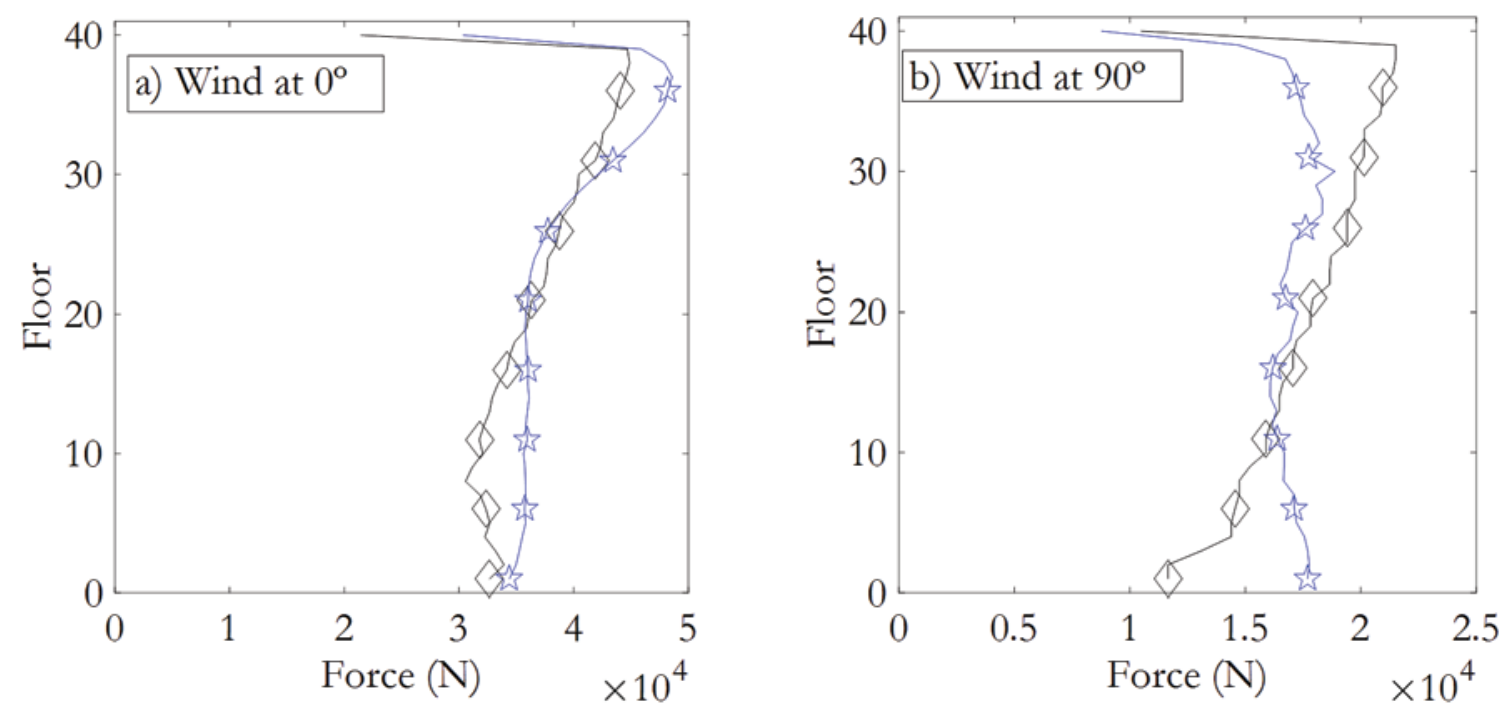

Wind Tunnel is Computer simulation

Figure 15

Drag force per floor: CFD and wind tunnel - wind incidence: $a) \varphi=0^{\circ}$ and $b$ ) $\varphi=90^{\circ}$ 
Table 6

Summary of simulations - 2D and 3D flow

\begin{tabular}{ccccc}
\hline Model & \multicolumn{3}{c}{ Drag coefficient $\left(\mathrm{C}_{\mathrm{D}}\right)$} \\
\cline { 2 - 5 } & CFD & Wind tunnel & $\begin{array}{c}\text { Theoretical value } \\
\text { Çengel and } \\
\text { Cimbala[30] }\end{array}$ & $\begin{array}{c}\text { Error } \\
(\%)\end{array}$ \\
\hline $01-$ Square section & 2.17 & - & 2.20 & 1.05 \\
02- Cube & 1.02 & - & 1.95 & 2.86 \\
$03-$ Real aqueduct & 1.93 & - & - & 1.03 \\
$04-$ Real building wind at $0^{\circ}$ & 0.91 & 0.86 & - & 5.81 \\
\hline
\end{tabular}

Table 7

Average time for each step - Mesh (04)

\begin{tabular}{ccccccc}
\hline Case & Geometry & Mesh & $\begin{array}{c}\text { Data and } \\
\text { premises }\end{array}$ & Processing & $\begin{array}{c}\text { Analysis } \\
\text { of results }\end{array}$ & Total time \\
\hline Model 3 & $0.5 \mathrm{~h}$ & $2.0 \mathrm{~h}$ & $0.5 \mathrm{~h}$ & $13.0 \mathrm{~h}$ & $1.0 \mathrm{~h}$ & $17 \mathrm{~h}$ \\
Model 4 & $1.0 \mathrm{~h}$ & $3.0 \mathrm{~h}$ & $1.0 \mathrm{~h}$ & $41.0 \mathrm{~h}$ & $2.0 \mathrm{~h}$ & $48 \mathrm{~h}$ \\
\hline
\end{tabular}

\section{Conclusions}

The proposed procedures resulted in a very efficient and objective guide, being recommended for preliminary analysis of buildings and special structures.

One of the requirements for the elaboration of this proposal was to carry out simulations using average computers. In this way, simplifications were necessary to meet hardware limitations. Another requirement imposed by this work was the use of numerical prototypes. The objective was to establish a series of criteria for several relevant variables in two and three-dimensional simulation of real structures.

This methodology was applied to the reference section (Model 01) where it presented an error of $1 \%$. Then, it was possible to apply these parameters to an aqueduct submitted to real wind inputs (Model 03), whose drag values presented an error of $1 \%$ in relation to the estimated theoretical value.

Flow simulations of the 3D reference model (Model 02) converged to a drag coefficient $C_{D}=1.02$, resulting in an error of only $3 \%$ over the theoretical value.

The real building (Model 04 ) presented an overall error of $6 \%$ for the incident wind at $0^{\circ}$ and $3 \%$ for the wind at $90^{\circ}$. In modeling, simplifications were made in the geometry described in Section 5 for the upper and lower floors. These approximations are confirmed in Figure 15, where the smaller error amplitudes appear at the intermediate floors, leaving the upper and lower ones with the largest errors, already highlighted in Table 5. It is noteworthy that for such building there were no reference values for the aerodynamic parameters. To reduce computational costs, it would be possible to carry out simulations using only mesh 04 , resulting in errors (in relation to mesh 05 ) of $1 \%$ for the incident wind at $0^{\circ}$ and $2 \%$ for incident wind at $90^{\circ}$. This would reduce simulation time by $40 \%$, about 48 hours, which proves to be a feasible value for design offices. In this way, the proposed procedures are very promising in terms of computational cost, drag estimation and versatility in changing problem variables, enabling a fast, low-cost companion to traditional wind tunnel tests.

\section{List of symbols}

$\vec{V}-$ Velocity vector

$\mu$ - Dynamic Viscosity

$\rho$ - Density

$v$ - Control volume

$d v$ - Infinitesimal volume

$S$ - Control surface

$v-$ Control domain

$\vec{\nabla}$ - Divergence

$\vec{f}$ - Effective force per unit mass within

$\mathrm{u}$ - Velocity in $\mathrm{x}$

$v$ - Velocity in $y$

$w$ - Velocity in z

$\mathrm{p}$ - Pressure

$g_{x, y, z}$ - Body accelerations

$f_{v}$ - Viscous forces acting on $\mathrm{dv}$

$\mathrm{V}$ - Averaged speed

$v$ - Kinematic viscosity

$D$ - Characteristic dimension of the immersed body

Z - Height

$Z_{0}$ - Roughness of the floor

$\mathrm{u}_{+}-$Friction velocity

$\mathrm{C}_{\mathrm{D}}$ - Drag coefficient

$\mathrm{k}$ - Von Karman constant

$\Delta \mathrm{t}$ - Time interval

$\Delta \mathrm{x}$ - Element size

$\varphi$ - Wind incidence angle

$\tau-$ Shear stress of the wind acting on the surface

\section{References}

[1] HALLEBRAND, E; JAKOBSSON, W. Structural design of high-rise buildings, Master dissertation, Department of construction sciences, LUND University, 2016.

[2] TAPAJÓS, L.S.; FERREIRA, J.A.T.; LIMA NETO, 
A.F.; REIXEIRA, M. R.; FERREIRA, M. P. Effect of Wind in the design of reiforced concrete buildings.In: RIEM- Ibracon structures and materials journal. V.9, 2016, p.883-910. ODA, D.A. Wind design loads on high-rise reinforced concrete buildings in Maysan province Shouthernlrac. In: International journal of innovative researche in science engineering and technology. V.6, n.7, 2017, p.12451-12471. ADNAN, A.; SURADI, S. Comparison on the effect of earthquake and wind loads on the performance of reinforced concrete buildings. In: Word conference on earthquake engineering. v.14, 2008.

[5] BHANDARI, N.M.; KRISHNA, P. ; KUMAR, K.. An explanatory handbook on proposed IS 875 (Part3) Wind load on buildings and structures. Shri G.S Institute of technology and science Indore. Document n IITK-GSDMA- Wind 06v3.0. 2011.

[6] BIASIOLI, F.; POLJANSEK,B.;NIKOLOVA, B.; DIMOVA, S and PINTO, A. Eurocode 2:Background and applications: Design of concrete buildings. Publications office, 2014.

[7] LAC- Laboratório de aerodinâmica de construções. Edifício Alfredo Volpi- João Pessoa, Túnel de vento Prof. Joaquim Blessmann, Porto Alegre, UFRGS, 2012. IPT- Instituto de Pesquisas Tecnológicas. Análise dinâmica da ação do vento no empreendimento Terra Brasilis Caruaru, CTMETRO- Centro de Metrologia mecânica, elétrica e de fluidos, São Paulo, 2014, relatório 138 649-205.

[9] BLOCKEN, B. 50 years of Computational Wind Engineering: Past, present and future, In: Journal of Wind Engineering and industrial Aerodynamics, 129, Cambridge, 2014 p.69-102.

[10] AKINS, R.E.; Peterka, J.A, CERMAK, J.E. Mean force and moment coefficiens for buildings in turbulent boundary layer, In:Journal of wind Engineering and Industrial Aerodynamics, v.2, 1977, p.195-209.

[11] BRAUN, A.L. e AWRUCH, A.M. Aerodynamic analysis of buldings using numerical tools from computational wind engineering, In: Associación Argentina de mecânica computational, v.26, 2007 p.1236-1251.

[12] BRAUN, A.L.; AWRUCH, A.M. Aerodynamic and aeroelastic analyses on the CAARC standard tall building model using numerical simulation. In: Computers and Structures, v.87, Porto Alegre, 2009, p.564-581.

[13] DAGNEW, A.K.; BITSUAMLAK, G.T. LES evaluation of Wind pressures on a standard tall building with and without a neighboring building. In: CWE-Computational Wind Engineering, Chapel Hill, North Carolina, 2010.

[14] DAGNEW, A.K.; BITSUAMLAK, G.T. Computational evaluation of Wind loads on a standard tall building using LES. In: Wind and structures, Techno-Press, 2014, p.567-598.

[15] OBERKAMPF, W.L.; T.G. TRUCANO, Verification and validation in computational fluid dynamics. Progress in Aerospace Sciences, v.38, 2002. p.209-272.

[16] CHEN, Q.; SREBRIC, J. A procedure for verification, validation, and reporting of indoor environment CFD analyses, In: HVAC\&R Research, v.8, n.2, 2002, p. 201-216.

[17] MOONEN, P.; BLOCKEN, B.; ROELS, S.; CARMELIET J. Numerical modeling of the flow conditions in a closed- circuit low-speed wind tunnel, In: International Journal of Wind Engineering and Industrial Aerodynamics, v.94, 2006, p.699-723.

[18] FRANKE, J.; HELLSTEN, A.; SCHLÜNZEN, H.; CARISSI$\mathrm{MO}, \mathrm{B}$., (Eds.). Best practice guideline for the CFD simulation of flows in the urban environment, In: COST- European Cooperation in Science and Technology, Action 732, 2007.

[19] REITER, S. Validation process for CFD simulations of Wind around buildings, In: EBECC- European Built Environment CAE (Computer-Aited Engineering) Conference, London, 2008.

[20] SCHATZMANN, M.; BRITTER, R. Quality assurance and improvement of micro-scale meteorological models, Int. Journal of environment and pollution, v.44, n.1-4, 2011, p.139-146.

[21] KIM, D. The application of CFD to building analysis and design: a combined approach of an immersive case study and wind tunnel testing, Dissertation, Faculty of the Virginia Polytechnic institute, Virginia, 2013.

[22] RONG, L.; NIELSEN, P.V.; BJERG, B. ZHANG, G.. Summary of best guidelines and validation of CFD modeling in livestock buildings to ensure prediction quality, In: Computers and Electronics in Agriculture, v.121, 2016, p.180-190.

[23] PATANKAR, V. Numerical heat transfer and fluid flow. Hemisphere publish corporation, 1980.

[24] PRAKASH, C.; PATANKAR, S.V. A control volume-based finite-element method for solvingthe Navier-Stokes equations using equal-order velocity-pressure interpolation, In: Numerical heat transfer, 8, 1985, p.229-280.

[25] VERSTEEG, H.K. MALALASEKERA,W. An excellent introduction to theory of CFD with well-presented derivations of the equations, Longman, Harlow, 1995.

[26] FERZIGER, J.H; PERIC, M. Computational Methods for Fluid Dynamics, 3, Springer, 2002.

[27] KUNDU, P.K.; COHEN, I.M. Fluid Mechanics, 2, Academic Press, 2002.

[28] LEWIS, R.W.; NITHIARASU, P.; SEETHARAMU, K.N. Fundamentals of the finite element method for heat and fluid flow. Wiley, 2004, p.217-218.

[29] ANSYS 14.0. Training Manual, Ansys, Incorporation, 2012.

[30] ÇENGEL, Y.A.; CIMBALA, J.M. Fluid Mechanics: Fundamentals and Applications. Mc Graw Hill, AMGH. 2007. 